\title{
Juvenile glaucoma
}

INSERM

\section{Source}

INSERM. (1999). Orphanet: an online rare disease and orphan drug data base. Juvenile glaucoma. ORPHA:98977

Juvenile glaucoma (JG) is a rare autosomal dominant open ang le glaucoma, characterized by early onset, severe elevation of intra ocular pressure of rapid progression, leading to optic nerve excavation and, when untreated, substantial visual impairment. 